\title{
PENERAPAN MODUL KONSELING KEHAMILAN TERHADAP PENINGKATAN SIKAP BIDAN DALAM KONSELING ANTENATAL CARE
}

\author{
Lely Firrahmawati, Sri Kustiyati \\ Dosen Sekolah Tinggi Ilmu Kesehatan 'Aisyiyah Surakarta
}

\begin{abstract}
ABSTRAK
Latar belakang: Pelayanan antenatal merupakan bagian penting dalam pelayanan kesehatan yang secara professional menyediakan upaya pencegahan dan meminimalkan risiko komplikasi dengan pemberian pendidikan kesehatan, konseling dan berbagai jenis intervensi pada ibu selama kehamilan. Tujuan: Menganalisis peningkatan sikap bidan dalam pemberian pelayanan antenatal care di wilayah Kabupaten Sragen, melalui penerapan modul konseling kehamilan oleh bidan terhadap ibu hamil yang melakukan antenatal care (ANC). Metode: Penelitian ini quasi experiment dengan pre-post test control group desain. Sampel pada penelitian untuk kelompok perlakuan dan kelompok kontrol masing-masing 23 bidan dan 69 ibu hamil di 15 Puskesmas Kabupaten Sragen. Pengujian statistik dengan kemaknaan hasil uji ditentukan berdasarkan nilai p<0,05 untuk analisis bivariabel menggunakan uji Wilcoxon, Chi Kuadrat, Mann Whitney. Hasil: Hasil uji statistik menggunakan Mann-Whitney skor pretest sikap pada kedua kelompok menunjukkan tidak ada perbedaan yang bermakna $(p>0,05)$. Untuk nilai postest terjadi perbedaan yang bermakna antara kelompok perlakuan dan kelompok kontrol nilai P-Value 0,000<5\%. Simpulan: Hasil analisis bivariat diketahui terdapat perbedaan yang bermakna/signifikan antara peningkatan sikap bidan antara kelompok bidan yang menggunakan modul dan tidak menggunakan modul di BPM wilayah Kabupaten Sragen Provinsi Jawa Tengah.
\end{abstract}

Kata kunci: modul konseling kehamilan, sikap.

\section{ABSTRACT}

Background: service antenatal is an important part of health services that is professional provide efforts to prevent and minimize risk complication by the provision of education health , counseling and various types of interventions on the during pregnancy. Purpose: analyze the increase in attitude midwives in provision of services antenatal care in the sragen regency, through the application of module counseling pregnancy by the midwife to pregnant women who performs antenatal care (ANC). A method of: this research quasi experiment with prepost test control group design. Samples to research to the treatment and control groups each 23 midwives and 69 pregnant women in 15 puskesmas sragen regency. Testing statistics with significancy test determined based on the $p<0,05$ for analysis bivariabel use wilcoxon test, chi square, for what whitney. The result: however statistical tests using mann-whitney score 


\section{GASTER Vol. XV No. 2 Agustus 2017}

pretest attitude in both groups indicated no difference meaningful $(p<0,05)$.To value postest happened meaningful differences between the treatment and control groups value p-value 0,000 $\&$ it; $5 \%$. Conclusions: the analysis bivariat known there is a difference meaningful / welfare between the increased attitude between the midwives using modules and not using module at bpm the district central java sragen province.

Keywords: module counseling pregnancy, attitude

\section{A. PENDAHULUAN}

Pelayanan antenatal merupakan bagian penting dalam pelayanan kesehatan yang secara profesional menyediakan upaya pencegahan dan meminimalkan risiko komplikasi dengan pemberian pendidikan kesehatan, konseling dan berbagai jenis intervensi pada ibu selama kehamilan (Nwaeze, 2013). Pelayanan Antenatal dapat membantu ibu hamil mengidentifikasi komplikasi yang terkait dengan kehamilan atau penyakit yang mungkin mempengaruhi kehamilan. Selama kunjungan antenatal, seorang wanita akan memperoleh berbagai intervensi yang diberikan oleh tenaga kesehatan, diantaranya adalah konseling tentang gaya hidup sehat, pemberian suplemen zat besi dan asam folat, serta imunisasi tetanus toksoid yang dapat mencegah kematian pada bayi baru lahir (Titaley, 2010). Di Indonesia, ibu hamil dianjurkan untuk menerima sedikitnya empat kali kunjungan antenatal, satu kali pada trimester pertama, satu kali pada trimester kedua dan dua kali di trimester ketiga. Standar minimum pelayanan yang diberikan meliputi pengukuran berat badan, tekanan darah, tinggi fundus uteri, Imunisasi Tetanus Toxoid (TT) dan pemberian suplemen zat besi/suplemen asam folat (Titaley, 2010).

Ibu hamil didalam pelayanan antenatal memperoleh kesempatan untuk memahami proses kehamilan, persalinan dan perawatan bayi baru lahir. Disamping pemeriksaan fisik rutin, deteksi dini komplikasi dan perawatan kehamilan, WHO juga menfokuskan model pelayanan antenatal yang menyediakan informasi dan konseling kepada seluruh ibu hamil yang terkait dengan kebutuhan wanita selama hamil, persalinan, persiapan menghadapi kegawatdaruratan, nutrisi, home care dan dukungan jika menghadapi tanda bahaya dan komplikasi (Jennings, 2010).

Komunikasi dalam pelayanan antenatal telah terbukti menjadi strategi yang efektif 
untuk meningkatkan pemahaman dan perilaku kesehatan ibu hamil. Di beberapa negara berkembang, dalam proses komunikasi informasi kurang cukup diberikan sehingga menyebabkan ketidaktahuan ibu hamil untuk mengambil tindakan. Beberapa penelitian tentang kualitas konseling antenatal menunjukkan kurang adekuatnya informasi yang diberikan selama konseling antenatal (hanya sekedar sharing, bukan informasi yang direkomendasikan sesuai pedoman konseling antenatal). Data yang ada menunjukkan bahwa pengetahuan pasien menjadi kurang karena komunikasi dalam konseling masih rendah (Jennings, 2010)

Studi di Ethiopia menunjukan bahwa ibu hamil tidak puas terhadap kualitas pelayanan antenatal yang diberikan, terkait dengan faktor privasi selama konseling, frekuensi kunjungan, waktu pemeriksaan, penjelasan prosedur selama pemeriksaan dan durasi untuk konsultasi (Ejigu, 2013). Beberapa penelitian lain menunjukan bahwa kualitas konseling antenatal masih rendah (konseling yang diberikan lebih kepada sharing pengalaman, bukan berdasarkan panduan yang direkomendasikan oleh WHO) (Anya, 2008). Data menunjukan bahwa pasien sering menganggap konseling ditujukan untuk orang miskin dan pengetahuan ibu yang kurang sering dikaitkan dengan komunikasi yang tidak efektif (Beck, 2002).

Penelitian yang dilakukan syafrani tahun 2004 di Jakarta Timur menunjukan bahwa pelaksanaan konseling antenatal masih sederhana dan hanya terfokus pada hal - hal khusus mengenai kehamilan yang disampaikan/ dikeluhkan pasien saat kunjungan antenatal, proses pemecahan masalah dan pengambilan keputusan belum dapat dilakukan, konseling dilakukan dalam waktu yang relatif singkat sehingga penggalian informasi dari pasien tidak maksimal (Ibrahim, 2004).

Berdasarkan penelitian di Niger tahun 2000, kualitas konseling antenatal untuk mendeteksi kelainan kehamilan sangat rendah, padahal 91\% faktor risiko dapat dideteksi dengan wawancara/konseling (Prual, 2000). Penelitian tentang strategi komunikasi yang efektif dalam pelayanan antenatal merupakan sebuah kebutuhan di negara berkembang untuk meningkatkan keterampilan konseling tenaga kesehatan tentang perawatan ibu dan bayi baru lahir. Upaya yang dilakukan untuk meningkatkan keterampilan komunikasi tenaga kesehatan dilakukan melalui pelatihan atau pendidikan lanjut. Namun, bukti terbaru 


\section{GASTER Vol. XV No. 2 Agustus 2017}

menunjukkan bahwa alat bantu untuk konseling dapat meningkatkan kinerja petugas kesehatan bila dikombinasikan dengan pelatihan dan supervisi. Alat bantu konseling adalah alat dukungan dengan informasi tertulis yang berupa gambar dan informasi. Dalam konteks konseling, alat bantu gambar dapat membantu tenaga kesehatan berkomunikasi dengan ibu hamil agar dapat mengingat pesan-pesan kunci. Alat bantu gambar ini juga dapat berfungsi untuk memfasilitasi proses komunikasi dengan menyampaikan ide-ide menggunakan gambar (Jennings, 2010).

Pemberian informasi kesehatan merupakan elemen penting dalam pelayanan antenatal. Namun, sebuah penelitian terbaru menunjukkan bahwa meskipun ibu hamil melakukan kunjungan antenatal berkali-kali, mereka tidak mendapatkan informasi yang cukup efektif mengenai perawatan selama kehamilan, persalinan dan nifas (Jennings, 2010).

Hasil penelitian yang dilakukan Jennings, et al tahun 2010 menunjukkan bahwa konten dari sebuah konseling dan teknik konseling yang benar secara signifikan dapat meningkatkan pengetahuan ibu hamil tentang persiapan persalinan, pengenalan tanda bahaya, persalinan yang aman dan perawatan bayi baru lahir. Implementasi dalam penelitian ini berkaitan dengan proses komunikasi dan penyediaan informasi tentang efektivitas dari suatu alat bantu konseling yang dapat digunakan oleh tenaga kesehatan (Jennings, 2010).

Alat bantu konseling memberikan bantuan kepada ibu hamil agar dapat membuat keputusan tentang kesehatan diri dan janinnya. Beberapa faktor kemungkinan dapat berkontribusi untuk perbaikan kualitas pelayanan konseling , Salah satu faktor yang dapat dijadikan pedoman dalam perbaikan kualitas pelayanan konseling diadaptasi dari Beninese yang mudah digunakan. Dalam desain tersebut terdapat pedoman praktis untuk berkomunikasi dan konsisten dengan keterampilan dan praktek yang ada, terorganisir dalam modul (untuk memprioritaskan pesan kunci), dan mampu memperlihatkan hasil. Pedoman ini telah terbukti dapat meningkatkan praktik pelaksanaan konseling yang berkualitas. Alat ini juga memudahkan komunikasi antara tenaga kesehatan dan wanita hamil serta relevan digunakan pada wanita yang buta aksara (Jennings, 2010).

Meskipun demikian, hambatan-hambatan dalam pelaksanaan konseling ditemukan 


\section{GASTER Vol. XV No. 2 Agustus 2017}

di beberapa daerah. Tenaga kesehatan melaporkan bahwa tidak adanya ruang khusus untuk konseling tetap menjadi tantangan bersama ditambah hambatan dalam bahasa (daerah dengan beberapa dialek). Selain itu, pemeriksaan fisik, pengelolaan kehamilan yang memerlukan banyak waktu dapat menghambat kualitas konseling antenatal. Kurangnya waktu konseling menjadi penghalang yang paling sering dilaporkan oleh tenaga kesehatan. Studi terbaru menunjukkan bahwa waktu konsultasi antenatal rendah di banyak negara berkembang. Beberapa petugas kesehatan menilai bahwa gambar sebenarnya dapat mengurangi waktu yang diperlukan untuk membrikan penjelasan saat konseling dan memungkinkan mereka untuk meningkatkan jumlah pesan yang ingin disampaikan. Namun, tantangan untuk dapat berkomunikasi secara efektif dalam waktu yang relatif singkat masih perlu di teliti (Jennings, 2010).

Tiga perempat perempuan dalam kelompok intervensi pada penelitian ini mengatakan mereka lebih suka memiliki banyak waktu untuk konseling yang diberikan tenaga kesehatan. Menjadi catatan penting adanya standardisasi dalam teknik komunikasi, karena masih adanya kelemahan pada pedoman yang kurang objektif. Upaya peningkatan perlu dilakukan untuk memastikan bahwa komunikasi berpusat pada pasien dan pedoman konseling yang digunakan bukan hanya panduan kontekstual dalam berkomunikasi (Jennings, 2010).

Konseling kesehatan ibu dan bayi adalah proses interaktif antara tenaga kesehatan yang terampil dengan seorang wanita dan keluarganya, dalam rangka pertukarkan informasi dan pemberian dukungan sehingga wanita dan keluarganya dapat membuat keputusan, merancang rencana dan mengambil tindakan untuk meningkatkan derajat kesehatan mereka.9 WHO telah mengembangkan instrumen yang membantu tenaga kesehatan untuk meningkatkan kemampuan (skills) mereka dalam memberikan konseling dan komunikasi yang efektif kepada perempuan dan kelaurganya dalam kunjungan rutin maupun emergensi selama kehamilan, persalinan, nifas dan periode pasca abortus. Konseling yang dapat mendukung perempuan dan keluarganya untuk mengaplikasikan informasi yang diperoleh dalam praktik keseharian untuk meningkatkan kualitas/derajat kesehatan mereka (WHO, 2013).

Beberapa penelitian tentang proses pelayanan dan konseling antenatal yang 


\section{GASTER Vol. XV No. 2 Agustus 2017}

berkualitas telah banyak dilakukan. Penelitian yang dilakukan Matejic, et al di Serbia tahun 2014 yang bertujuan menganalisis faktorfaktor yang mempengaruhi kepuasan dan harapan ibu hamil dalam pelayanan antenatal menunjukan hasil bahwa 74,6\% ibu hamil puas dengan pelayanan konseling yang diberikan oleh tenaga kesehatan. Secara umum, ada tiga faktor yang mempengaruhi kepuasan ibu, yaitu faktor lingkungan, kompetensi profesional tenaga kesehatan dan kemampuan komunikasi dan konseling tenaga kesehatan. Faktor kemampuan dan konseling tenaga kesehatan yang memuaskan berdasarkan penelitian diatas adalah sikap pengertian bidan, proses komunikasi bidan yang melakukan komunikasi dua arah dengan klien, mampu membangun hubungan interpersonal yang baik, bidan memiliki karakteristik yang mampu memberi dukungan, ramah, penuh perhatian, hormat dan tidak menghakimi adalah karakteristik yang paling diinginkan oleh pasien (Matejic, 2014).

\section{B. RUMUSAN MASALAH}

Pelayanan antenatal merupakan bagian penting dalam pelayanan kesehatan yang secara profesional menyediakan upaya pencegahan dan meminimalkan risiko komplikasi dengan pemberian pendidikan kesehatan, konseling dan berbagai jenis intervensi pada ibu selama kehamilan (Nwaeze, 2013). Pelayanan Antenatal dapat membantu ibu hamil mengidentifikasi komplikasi yang terkait dengan kehamilan atau penyakit yang mungkin mempengaruhi kehamilan. Selama kunjungan antenatal, seorang wanita akan memperoleh berbagai intervensi yang diberikan oleh tenaga kesehatan, diantaranya adalah konseling tentang gaya hidup sehat, pemberian suplemen zat besi dan asam folat, serta imunisasi tetanus toksoid yang dapat mencegah kematian pada bayi baru lahir (Titaley, 2010). Di Indonesia, ibu hamil dianjurkan untuk menerima sedikitnya empat kali kunjungan antenatal, satu kali pada trimester pertama, satu kali pada trimester kedua dan dua kali di trimester ketiga. Standar minimum pelayanan yang diberikan meliputi pengukuran berat badan, tekanan darah, tinggi fundus uteri, Imunisasi Tetanus Toxoid (TT) dan pemberian suplemen zat besi/suplemen asam folat (Titaley, 2010).

Ibu hamil didalam pelayanan antenatal memperoleh kesempatan untuk memahami proses kehamilan, persalinan dan perawatan bayi baru lahir. Disamping pemeriksaan fisik rutin, deteksi dini komplikasi dan perawatan 
kehamilan, WHO juga menfokuskan model pelayanan antenatal yang menyediakan informasi dan konseling kepada seluruh ibu hamil yang terkait dengan kebutuhan wanita selama hamil, persalinan, persiapan menghadapi kegawatdaruratan, nutrisi, home care dan dukungan jika menghadapi tanda bahaya dan komplikasi (Jennings, 2010).

Komunikasi dalam pelayanan antenatal telah terbukti menjadi strategi yang efektif untuk meningkatkan pemahaman dan perilaku kesehatan ibu hamil. Di beberapa negara berkembang, dalam proses komunikasi informasi kurang cukup diberikan sehingga menyebabkan ketidaktahuan ibu hamil untuk mengambil tindakan. Beberapa penelitian tentang kualitas konseling antenatal menunjukkan kurang adekuatnya informasi yang diberikan selama konseling antenatal (hanya sekedar sharing, bukan informasi yang direkomendasikan sesuai pedoman konseling antenatal). Data yang ada menunjukkan bahwa pengetahuan pasien menjadi kurang karena komunikasi dalam konseling masih rendah (Jennings, 2010)

Studi di Ethiopia menunjukan bahwa ibu hamil tidak puas terhadap kualitas pelayanan antenatal yang diberikan, terkait dengan faktor privasi selama konseling, frekuensi kunjungan, waktu pemeriksaan, penjelasan prosedur selama pemeriksaan dan durasi untuk konsultasi (Ejigu, 2013). Beberapa penelitian lain menunjukan bahwa kualitas konseling antenatal masih rendah (konseling yang diberikan lebih kepada sharing pengalaman, bukan berdasarkan panduan yang direkomendasikan oleh WHO) (Anya, 2008). Data menunjukan bahwa pasien sering menganggap konseling ditujukan untuk orang miskin dan pengetahuan ibu yang kurang sering dikaitkan dengan komunikasi yang tidak efektif (Beck, 2002).

Penelitian yang dilakukan syafrani tahun 2004 di Jakarta Timur menunjukan bahwa pelaksanaan konseling antenatal masih sederhana dan hanya terfokus pada hal - hal khusus mengenai kehamilan yang disampaikan/ dikeluhkan pasien saat kunjungan antenatal, proses pemecahan masalah dan pengambilan keputusan belum dapat dilakukan, konseling dilakukan dalam waktu yang relatif singkat sehingga penggalian informasi dari pasien tidak maksimal (Ibrahim, 2004).

Berdasarkan penelitian di Niger tahun 2000, kualitas konseling antenatal untuk mendeteksi kelainan kehamilan sangat rendah, padahal $91 \%$ faktor risiko dapat dideteksi 


\section{GASTER Vol. XV No. 2 Agustus 2017}

dengan wawancara/konseling (Prual, 2000). Penelitian tentang strategi komunikasi yang efektif dalam pelayanan antenatal merupakan sebuah kebutuhan di negara berkembang untuk meningkatkan keterampilan konseling tenaga kesehatan tentang perawatan ibu dan bayi baru lahir. Upaya yang dilakukan untuk meningkatkan keterampilan komunikasi tenaga kesehatan dilakukan melalui pelatihan atau pendidikan lanjut. Namun, bukti terbaru menunjukkan bahwa alat bantu untuk konseling dapat meningkatkan kinerja petugas kesehatan bila dikombinasikan dengan pelatihan dan supervisi. Alat bantu konseling adalah alat dukungan dengan informasi tertulis yang berupa gambar dan informasi. Dalam konteks konseling, alat bantu gambar dapat membantu tenaga kesehatan berkomunikasi dengan ibu hamil agar dapat mengingat pesan-pesan kunci. Alat bantu gambar ini juga dapat berfungsi untuk memfasilitasi proses komunikasi dengan menyampaikan ide-ide menggunakan gambar (Jennings, 2010).

Pemberian informasi kesehatan merupakan elemen penting dalam pelayanan antenatal. Namun, sebuah penelitian terbaru menunjukkan bahwa meskipun ibu hamil melakukan kunjungan antenatal berkali-kali, mereka tidak mendapatkan informasi yang cukup efektif mengenai perawatan selama kehamilan, persalinan dan nifas (Jennings, 2010).

Hasil penelitian yang dilakukan Jennings, et al tahun 2010 menunjukkan bahwa konten dari sebuah konseling dan teknik konseling yang benar secara signifikan dapat meningkatkan pengetahuan ibu hamil tentang persiapan persalinan, pengenalan tanda bahaya, persalinan yang aman dan perawatan bayi baru lahir. Implementasi dalam penelitian ini berkaitan dengan proses komunikasi dan penyediaan informasi tentang efektivitas dari suatu alat bantu konseling yang dapat digunakan oleh tenaga kesehatan (Jennings, 2010).

Alat bantu konseling memberikan bantuan kepada ibu hamil agar dapat membuat keputusan tentang kesehatan diri dan janinnya. Beberapa faktor kemungkinan dapat berkontribusi untuk perbaikan kualitas pelayanan konseling, Salah satu faktor yang dapat dijadikan pedoman dalam perbaikan kualitas pelayanan konseling diadaptasi dari Beninese yang mudah digunakan. Dalam desain tersebut terdapat pedoman praktis untuk berkomunikasi dan konsisten dengan 
keterampilan dan praktek yang ada, terorganisir dalam modul (untuk memprioritaskan pesan kunci), dan mampu memperlihatkan hasil. Pedoman ini telah terbukti dapat meningkatkan praktik pelaksanaan konseling yang berkualitas. Alat ini juga memudahkan komunikasi antara tenaga kesehatan dan wanita hamil serta relevan digunakan pada wanita yang buta aksara (Jennings, 2010).

Meskipun demikian, hambatan-hambatan dalam pelaksanaan konseling ditemukan di beberapa daerah. Tenaga kesehatan melaporkan bahwa tidak adanya ruang khusus untuk konseling tetap menjadi tantangan bersama ditambah hambatan dalam bahasa (daerah dengan beberapa dialek). Selain itu, pemeriksaan fisik, pengelolaan kehamilan yang memerlukan banyak waktu dapat menghambat kualitas konseling antenatal. Kurangnya waktu konseling menjadi penghalang yang paling sering dilaporkan oleh tenaga kesehatan. Studi terbaru menunjukkan bahwa waktu konsultasi antenatal rendah di banyak negara berkembang. Beberapa petugas kesehatan menilai bahwa gambar sebenarnya dapat mengurangi waktu yang diperlukan untuk membrikan penjelasan saat konseling dan memungkinkan mereka untuk meningkatkan jumlah pesan yang ingin disampaikan. Namun, tantangan untuk dapat berkomunikasi secara efektif dalam waktu yang relatif singkat masih perlu di teliti (Jennings, 2010).

Tiga perempat perempuan dalam kelompok intervensi pada penelitian ini mengatakan mereka lebih suka memiliki banyak waktu untuk konseling yang diberikan tenaga kesehatan. Menjadi catatan penting adanya standardisasi dalam teknik komunikasi, karena masih adanya kelemahan pada pedoman yang kurang objektif. Upaya peningkatan perlu dilakukan untuk memastikan bahwa komunikasi berpusat pada pasien dan pedoman konseling yang digunakan bukan hanya panduan kontekstual dalam berkomunikasi (Jennings, 2010).

Konseling kesehatan ibu dan bayi adalah proses interaktif antara tenaga kesehatan yang terampil dengan seorang wanita dan keluarganya, dalam rangka pertukarkan informasi dan pemberian dukungan sehingga wanita dan keluarganya dapat membuat keputusan, merancang rencana dan mengambil tindakan untuk meningkatkan derajat kesehatan mereka.9 WHO telah mengembangkan instrumen yang membantu tenaga kesehatan untuk meningkatkan kemampuan (skills) 


\section{GASTER Vol. XV No. 2 Agustus 2017}

mereka dalam memberikan konseling dan komunikasi yang efektif kepada perempuan dan kelaurganya dalam kunjungan rutin maupun emergensi selama kehamilan, persalinan, nifas dan periode pasca abortus. Konseling yang dapat mendukung perempuan dan keluarganya untuk mengaplikasikan informasi yang diperoleh dalam praktik keseharian untuk meningkatkan kualitas/ derajat kesehatan mereka (WHO, 2013).

Beberapa penelitian tentang proses pelayanan dan konseling antenatal yang berkualitas telah banyak dilakukan. Penelitian yang dilakukan Matejic, et al di Serbia tahun 2014 yang bertujuan menganalisis faktorfaktor yang mempengaruhi kepuasan dan harapan ibu hamil dalam pelayanan antenatal menunjukan hasil bahwa $74,6 \%$ ibu hamil puas dengan pelayanan konseling yang diberikan oleh tenaga kesehatan. Secara umum, ada tiga faktor yang mempengaruhi kepuasan ibu, yaitu faktor lingkungan, kompetensi profesional tenaga kesehatan dan kemampuan komunikasi dan konseling tenaga kesehatan. Faktor kemampuan dan konseling tenaga kesehatan yang memuaskan berdasarkan penelitian diatas adalah sikap pengertian bidan, proses komunikasi bidan yang melakukan komunikasi dua arah dengan klien, mampu membangun hubungan interpersonal yang baik, bidan memiliki karakteristik yang mampu memberi dukungan, ramah, penuh perhatian, hormat dan tidak menghakimi adalah karakteristik yang paling diinginkan oleh pasien (Matejic, 2014).

\section{HASIL DAN PEMBAHASAN}

Tabel 1. Karakteristik Pada Subjek Penelitian Bidan

\begin{tabular}{|c|c|c|c|}
\hline \multirow{2}{*}{ Karakteristik } & \multicolumn{2}{|l|}{ Kelompok } & \multirow[t]{2}{*}{ Nilai $p$} \\
\hline & $\begin{array}{l}\text { Perlakuan } \\
(n=23)\end{array}$ & $\begin{array}{l}\text { Kontrol } \\
(n=23)\end{array}$ & \\
\hline 1. Umur (tahun) & & & $0,001^{*}$ \\
\hline$<30$ & 1 & 2 & \\
\hline $30-39$ & 3 & 14 & \\
\hline $40-49$ & 18 & 7 & \\
\hline$>50$ & 1 & 0 & \\
\hline Mean (SD) & $41,4(5,7)$ & $35,6(5,3)$ & \\
\hline Median (Rentang) & $25-55$ & $26-46$ & \\
\hline 2. Masa Kerja (tahun) & & & $0,007 * *$ \\
\hline$\leq 10$ & 2 & 11 & \\
\hline$<10$ & 21 & 12 & \\
\hline Mean (SD) & $20,3(6,2)$ & $12,3(5,7)$ & \\
\hline Median (Rentang) & $1-33$ & $2-21$ & \\
\hline
\end{tabular}

Keterangan uji : *) Uji Mann Whithney dan **) Uji Chi Kuadrat

Hasil uji statistik tersebut diperoleh nilai $\mathrm{p}<0,05$, maka dapat disimpulkan bahwa terdapat perbedaan pada umur dan masa kerja bidan antara kelompok perlakuan dan kelompok control. 
Tabel 2. Karakteristik Pada Subjek Penelitian Ibu Hamil

\begin{tabular}{|c|c|c|c|}
\hline \multirow[b]{2}{*}{ Karakteristik } & \multicolumn{2}{|l|}{ Kelompok } & \multirow[t]{2}{*}{ Nilai $p$} \\
\hline & $\begin{array}{l}\text { Perlakuan } \\
(\mathrm{n}=69)\end{array}$ & $\begin{array}{l}\text { Kontrol } \\
(\mathrm{n}=69)\end{array}$ & \\
\hline 1. Umur (tahun) & & & $0.885^{*}$ \\
\hline$<20$ & 2 & 3 & \\
\hline $20-30$ & 55 & 55 & \\
\hline$>30$ & 12 & 11 & \\
\hline \multirow{5}{*}{$\begin{array}{ll}\text { 2. } & \text { Pendidikan } \\
\text { SD } \\
\text { SMP } \\
\text { SMA } \\
\text { PT }\end{array}$} & & & $0,938^{*}$ \\
\hline & 9 & 7 & \\
\hline & 30 & 33 & \\
\hline & 28 & 27 & \\
\hline & 2 & 2 & \\
\hline \multicolumn{3}{|l|}{ 3. Pekerjaan } & $1,0^{*}$ \\
\hline Bekerja & 11 & 12 & \\
\hline Tidak bekerja & 58 & 57 & \\
\hline \multicolumn{3}{|l|}{ 4. Paritas } & $0,842 *$ \\
\hline I & 26 & 23 & \\
\hline II & 30 & 31 & \\
\hline$>$ III & 13 & 15 & \\
\hline
\end{tabular}

Keterangan uji : *) Uji Chi Kuadrat

Hasil uji statistik tersebut diperoleh nilai $p$ $>0,05$, maka dapat disimpulkan bahwa tidak terdapat perbedaan pada umur, pendidikan, pekerjaan dan paritas antara kedua kelompok penelitian, sehingga secara statistik homogen serta layak untuk dibandingkan.

Tabel 3. Perbedaan Skor Sikap Pre dan Post Bidan Antara Kedua Kelompok Penelitian

\begin{tabular}{lllll}
\hline $\begin{array}{l}\text { Skor Sikap } \\
\text { (Skala 100) }\end{array}$ & \begin{tabular}{l} 
Kelompok \\
\cline { 2 - 3 }
\end{tabular} & $\begin{array}{l}\text { Perlakuan } \\
(\mathbf{n}=\mathbf{2 3})\end{array}$ & $\begin{array}{l}\text { Kontrol } \\
(\mathbf{n}=\mathbf{2 3})\end{array}$ & \\
\hline a. & Pre & $15,9(2,6)$ & $14,9(2,5)$ & $0,007^{*}$ \\
& $\begin{array}{l}\text { Mean (SD) } \\
\text { Median (Rentang) }\end{array}$ & $17(10-24)$ & $15(9-24)$ & \\
\hline b. & $\begin{array}{l}\text { Post } \\
\text { Mean (SD) }\end{array}$ & $28,2(1,5)$ & $15(2,6)$ & $<0,001^{*}$ \\
& Median (Rentang) & $28(20-30)$ & $15(9-24)$ & \\
\hline c. & $\begin{array}{l}\text { Perbandingan sikap } \\
\text { pre dan post }\end{array}$ & $\mathrm{p}=<0,001^{* *} \mathrm{p}=<0,002^{* *}$ & \\
\hline
\end{tabular}

Keterangan uji : *) Uji Mann Whitney; **) Wilcoxon
Dari tabel 3 menunjukkan bahwa skor pretest sikap pada kedua kelompok menunjukkan tidak ada perbedaan yang bermakna $(p>0,05)$. Untuk nilai postest terjadi perbedaan yang bermakna antara kelompok perlakuan dan kelompok kontrol $(p<0,001)$. Nilai median pretest sikap kelompok perlakuan 17 sedangkan nilai median posttest meningkat menjadi 28, hal ini menunjukkan bahwa ada peningkatan sikap yang bermakna $p<0,001$. Nilai median pretest keterampilan kelompok kontrol 15 sedangkan nilai median posttest tetap 15 .

Parasuraman, Zeithamal dan Barry (1996) mengidentifikasi salah satu dimensi pokok yang berkaitan dengan kualitas pelayanan yaitu jaminan/keyakinan yang meliputi pengetahuan dan kesopanan bidan serta kemampuan mereka untuk menimbulkan kepercayaan dan keyakinan (Wijono, 1999).

Faktor kemampuan dan konseling tenaga kesehatan yang memuaskan berdasarkan penelitian diatas adalah sikap pengertian bidan, proses komunikasi bidan yang melakukan komunikasi dua arah dengan klien, mampu membangun hubungan interpersonal yang baik, bidan memiliki karakteristik yang mampu memberi dukungan, ramah, penuh perhatian, hormat dan tidak menghakimi adalah karakteristik yang paling diinginkan oleh pasien (Mateji, 2014). 


\section{GASTER Vol. XV No. 2 Agustus 2017}

Snock (1981) menyatakan diperlukan petugas-petugas yang mempunyai dedikasi tinggi, terampil, ramah, sopan simpatik, luwes, penuh pengertian, mempunyai kemampuan berkomunikasi dengan baik. Seperti halnya penelitian yang dilakukan oleh Johana bahwa terdapat hubungan Antara pelayanan kesehatan berupa pemeriksaan kehamilan dengan kepuasaan ibu hamil terhadap kualitas pelayanan kesehatan yang diterimanya (Payne, 2000).

Pace dan Faules (2006) berpendapat bahwa kepuasaan komunikasi yang biasanya berkenaan dengan kenyamanan yang berarti individu merasa nyaman dengan pesan, media, hubungan atas hasil-hasil yang diinginkan (Wayner, 2006).

Tabel 4. Perbedaan Skor Peningkatan Sikap antara Kelompok Perlakuan dan Kelompok Intervensi

\begin{tabular}{lllll}
\hline & $\begin{array}{l}\text { Mean } \\
\text { Rank }\end{array}$ & $\begin{array}{l}\text { Sum } \\
\text { Rank }\end{array}$ & $\begin{array}{l}\text { Koefisien } \\
\text { Z }\end{array}$ & Nilai \\
\hline Perlakuan 104 & 7176 & $-10,571$ & 0,000 \\
\hline Kontrol & 35 & 2415 & & \\
\hline
\end{tabular}

Ket: diuji dengan Uji Mann-Whitney

Berdasarkan tabel 4 menunjukkan mean rank untuk data sikap pada saat postest untuk kelompok kontrol sebesar 35 sedangkan mean rank untuk sikap pada saat postets untuk kelompok perlakuan sebesar 104. Dengan masing-masing sum of ranks kelompok kontrol sebesar 2415 dan untuk kelompok kontrol sebesar 7176 Berdasarkan data untuk mean ranks diketahui bahwa sikap pada kelompok kontrol sebesar 35 lebih kecil dari pada mean ranks kelompok perlakuan sebesar 104 maka berarti menunjukkan bahwa sikap antara kelompok perlakuan dan kelompok kontrol untuk sesudah diberikan perlakuan menunjukkan lebih besar kelompok perlakuan. Hasil nilai koefisien Z sebesar 10,571 dan Asym.Sig (nilai p) sebesar 0,000. Hal ini menunjukkan bahwa nilai Asym.Sig (nilai $\mathrm{p}$ ) $<0,05$ maka Ho ditolak. Jadi dapat diambil kesimpulan bahwa ada perbedaan yang signifikan sikap antara kelompok yang menggunakan modul dan tidak menggunakan modul konseling kehamilan.

\section{SIMPULAN DAN SARAN}

Berdasarkan hasil analisis dan pembahasan yang telah dilakukan serta konsistensi terhadap tujuan penelitian, maka diperoleh simpulan Ada perbedaan signifikan sikap konseling kehamilan dengan penerapan modul konseling kehamilan trimester I dengan nilai p sebesar 0,000 hal ini menunjukkannilai $\mathrm{p}<0,05$. Saran dari peneliti yaitu perlunya standarisasi pedoman konseling kehamilan dalam upaya meningkatkan pengetahuan, siakp dan keterampilan konseling bidan dalam memberikan pelayanan konseling kehamilan. 


\section{DAFTAR PUSTAKA}

Anya SE, Hydara A, Jaiteh LE: Antenatal Care in the Gambia: Missed opportunity for information, education and communication. BMC Pergnancy and Childbirth 2008, 8:9.

Beck R, Daughtridge R, Sloane P: Physician-patient communication in the primary care office: a systematic review. J Am Board Fam Pract 2002, 15(1):25-38, review.

Department of Maternal, Newborn, Child and Adolescent Health. A handbook for building skills: counselling for maternal and newborn health care. World Health Organization. 2013;ISBN 9789241547628

Ejigu T, Woldie M, Kifle Y. Quality of antenatal care services at public health facilities of Bahir-Dar special zone, Northwest Ethiopia. Journal of BMC Health Services Research. $2013 ; 13(443)$

Ibrahim S. Analisis terhadap pelaksanaan konseling kehamilan oleh bidan di Puskesmas Kecamatan Wilayah Jakarta Timur. Tesis FKM Universitas Indonesia. 2004

Jennings L, Yebadokpo AS, Affo J, Agbogbe M. Antenatal counseling in maternal and newborn care: use of job aids to improve health worker performance and maternal understanding in Benin. Journal of BMC Pregnancy and Childbirth. 2010;10(75)

Matejic B, Milicevic MS, Vasic V, Djikanovic B. Maternal satisfaction with organized perinatal care in Serbian Public Hospitals. Journal of BMC Pregnancy and Childbirth. 2014;14(14)

Maulana. Penilaian Kepuasaan Ibu Hamil Terhadap Mutu layanan Antenatal Dalam Kaitannya Dengan Kepatuhan Dan Karakteristik Bidan Di Puskesmas Se Kota Jambi Tahun 2011. Tesis Fakultas Kesehatan Masyarakat Universitas Indonesia. 2011.

Mateji B, Milena Š, Vasi V, Djikanovi B. Maternal satisfaction with organized perinatal care in Serbian public hospitals. BMC Pregnancy Childbirth. 2014;14(14). doi:10.1186/14712393-14-14. 2000

Nwaeze IL, Enabor OO, Oluwasola TAO, Aimakhu CO. Perception and satisfaction with quality of antenatal care services among pregnant women at the University College Hospital, Ibadan, Nigeria. Ann Ibd. Pg. Med. 2013; 11(1):22-28. 


\section{GASTER Vol. XV No. 2 Agustus 2017}

Prual A, Toure A, Huguet D, Laurent Y. The quality of risk factor screening during antenatal consultation in Niger. Oxford University Press. 2000;15(1): 11-16

Payne A. Service Marketing, Pemasaran Jasa. (ANDI, ed.). Yogyakarta;

Titaley CR, Hunter CL, Heywood P, Dibley MJ. Why don't some women attend antenatal and postnatal care services? : a qualitative study ofcommunity members' perspectives in Garut, Sukabumi and Ciamis districts of West Java Province, Indonesia. BMC Pregnancy Childbirth. 2010;10(61)

Wijono D. Manajemen Mutu Pelayanan Kesehatan. Jakarta: Air Langga University; 1999.

Wayner. P\&DFF. Komunikasi Organisasi. Bandung: PT Remaja Rosdakarya; 2006.

120 Penerapan Modul Konseling Kehamilan ... 